\title{
EEG findings in dementia with Lewy bodies and Alzheimer's disease
}

\author{
R C G Briel, I G McKeith, W A Barker, Y Hewitt, R H Perry, P G Ince, A F Fairbairn
}

Institute for the Health of the Elderly, Newcastle General Hospital, Westgate Road, Newcastle upon Tyne NE4 6BE, UK R C G Briel I G McKeith R H Perry P G Ince

A F Fairbairn

Department of Neuropsychiatry, Hadrian Clinic, Newcastle General Hospital, Newcastle upon Tyne NE4 6BE, UK

W A Barker

Department of Clinical Neurophysiology, Royal Victoria Infirmary and Associated Hospitals NHS Trust, Queen Victoria Road,

Newcastle upon Tyne, UK

Y Hewitt

Correspondence to: Dr R Briel, Institute for Health of the Elderly, Newcastle General Hospital, Westgate Road, Newcastle upon Tyne NE4 6BE, UK Telephone 0044191256 3018; fax 0044191273 1156.

Received 6 November 1998 and in final form 28 August 1998

Accepted 11 September 1998

\begin{abstract}
Objectives-To evaluate the role of the EEG in the diagnosis of dementia with Lewy bodies (DLB).

Methods-Standard EEG recordings from 14 patients with DLB confirmed at postmortem were examined and were compared with the records from 11 patients with Alzheimer's disease confirmed at postmortem

Results-Seventeen of the total of 19 records from the patients with DLB were abnormal. Thirteen showed loss of alpha activity as the dominant rhythm and half had slow wave transient activity in the temporal lobe areas. This slow wave transient activity correlated with a clinical history of loss of consciousness. The patients with Alzheimer's disease were less likely to show transient slow waves and tended to have less marked slowing of dominant rhythm. Conclusions-The greater slowing of the EEG in DLB than in Alzheimer's disease may be related to a greater loss of choline acetyltransferase found in DLB. Temporal slow wave transients may be a useful diagnostic feature in DLB and may help to explain the transient disturbance of consciousness which is characteristic of the disorder.

(F Neurol Neurosurg Psychiatry 1999;66:401-403)
\end{abstract}

Keywords: electroencephalography, dementia, Lewy body

Dementia with Lewy bodies (DLB) has recently been described as the second most common pathological type of dementia, accounting for up to $20 \%$ of elderly hospitalised patients coming to postmortem. ${ }^{12}$ Many patients with DLB, however, are probably often erroneously misdiagnosed as having senile dementia of Alzheimer type (SDAT) or toxic delirium. ${ }^{3}$ This difficulty in clinical diagnosis may now be partly overcome given the growing consensus about clinical diagnostic criteria ${ }^{4}$; however, their prospective utility and the role of investigative methods in enhancing accuracy of clinical diagnosis have yet to be evaluated.

The EEG is often carried out as part of the clinical assessment of patients with dementia as a non-invasive, widely available procedure which is generally well tolerated, even by patients with cognitive impairment. The EEG findings, which may support a diagnosis of Alzheimer's disease are slowing of alpha activity and an increase in slow frequency activity. ${ }^{5}$ These findings may also differentiate dementing disorders from metabolic or toxic confusional states. Findings of EEG previously reported in a few patients with $\mathrm{DLB}^{6-11}$ suggested that in addition to generalised slowing, sharp or triphasic waves may be characteristic features useful in clinical diagnosis.

There are pragmatic reasons to predict focal EEG abnormalities of the temporal lobe in DLB. The predilection sites for neuropathological change in DLB are in subcortical and temporal lobe structures and in addition, the hallucinations and loss of consciousness which are seen in some cases are often reminiscent of temporal lobe dysfunction, as seen, for example, in temporal lobe epilepsy.

The purpose of this study was to describe the characteristic EEG findings in a group of cases of DLB confirmed by postmortem, specifically looking for evidence of focal abnormalities in the temporal lobes, or for triphasic or sharp waves, and to compare these records with those from cases of SDAT confirmed by postmortem.

\section{Subjects and methods}

Fourteen cases of DLB confirmed by postmortem were selected on the basis of the availability of EEG records and 11 patients with SDAT were similarly available for comparison. The patients, who were aged between 64 and 89 at the time of EEG, were all from Newcastle hospitals and had died between 1984 and 1991. Neuropathological diagnosis was made according to previously published methods. ${ }^{12}$ All of the patients had been comprehensively assessed in a specialist psychogeriatric unit where EEGs are carried out on all patients as part of a routine dementia assessment. Standard EEG techniques were used.

The EEG records were examined blind to diagnosis on two occasions by three raters. The raters knew that the patients had dementia but had no other clinical details. The EEGs were assessed on the following criteria: dominant frequency, presence of other frequencies, left/ right asymmetry, mean amplitude, and presence of focal abnormalities including spikes, sharp waves, triphasic waves or transient slow wave activity. 
Case notes were examined using a specially designed standardised schedule to record specific clinical features. The duration of illness was identified as being the time between first onset of symptoms, as reported by the care giver and the date of the EEG, given in months. The timing of the EEG was also expressed as a percentage of the total period from onset to death. It was noted whether the patients either experienced episodic loss of consciousness, or hallucinations. A global rating scale of severity at the time of the EEGs was made using the clinical dementia rating (CDR) of Hughes et $\mathrm{al}^{13}$ (a score of 0 indicates no dementia, 0.5 indicates possible dementia, 1 indicates mild dementia, 2 indicates moderate dementia, and 3 indicates severe dementia).

Finally, clinical symptoms were examined for correlations with pathological diagnosis and EEG findings. The data were analysed using the statistical package for the social sciences (SPSS). When more than one variable was compared, correlation coefficients and $t$ values are given.

\section{Results}

The DLB group contained seven men and seven women, the SDAT group five men and six women. Individual case details are given in the table. Three $(21 \%)$ of the patients with DLB had been diagnosed as having Parkinson's disease before developing dementia (Parkinson's disease+DLB). The two groups were similar in age distribution (SDAT mean 73.4 (SD 10.21) years, DLB mean 78.1 (SD 7.24) years).

The DLB group had a slightly shorter duration of illness at the time of EEG (DLB mean 20.1 (SD 16.9) months), SDAT mean 31.4 (SD 15.6) months $(\mathrm{p}=0.100)$. When the timing of the EEG was expressed as the time of onset to EEG divided by time of onset to death, the two groups were similar (DLB mean (SD 25.2) $59.3 \%$, SDAT mean (SD 22.9) $52.9 \%$, Mann Whitney $U=64$ (NS)). The distribution of CDR scores was similar at the time of EEG suggesting an equivalent degree of impairment between the two groups. No patient had a history suggestive of clinical seizures.

The EEG records of these 25 patients were examined and are referred to by the case num-

Electroencephalographic and clinical features of patients with dementia with Lewy bodies and senile dementia of Alzheimer type

\begin{tabular}{|c|c|c|c|c|c|c|c|c|c|c|}
\hline Case No & $\begin{array}{l}\text { Age at } \\
\text { EEG } \\
(y)\end{array}$ & $\begin{array}{l}\text { Time from onset } \\
\text { of clinical } \\
\text { symptoms to } \\
\text { death (months) }\end{array}$ & $\begin{array}{l}\text { Clinical } \\
\text { dementia } \\
\text { rating }\end{array}$ & Hallucinations & $\begin{array}{l}\text { Episodic loss of } \\
\text { consciousness }\end{array}$ & $\begin{array}{l}\text { Time from onset } \\
\text { of clinical } \\
\text { symptoms to date } \\
\text { of EEG recording } \\
\text { (months) }\end{array}$ & $\begin{array}{l}\text { Time of onset } \\
\text { to EEG as \% } \\
\text { onset to death }\end{array}$ & $\begin{array}{l}\text { Dominant } \\
\text { activity }\end{array}$ & $\begin{array}{l}\text { Other } \\
\text { frequencies }\end{array}$ & $T L S W T$ \\
\hline \multicolumn{11}{|l|}{ SDAT Patients: } \\
\hline 1 & 80 & 99 & 1 & No & No & 60 & 61 & Alpha & Beta Theta & No \\
\hline 2 & 76 & 108 & 0.5 & No & No & 36 & 33 & Alpha & Theta Beta & No \\
\hline $3^{1}$ & 64 & 96 & 2 & No & Yes & 47 & 49 & Delta & Theta & Yes $\mathrm{L} / \mathrm{R}$ \\
\hline 4 & 76 & 19 & 2 & Auditory & No & 16 & 84 & Alpha & $\begin{array}{l}\text { Theta } \\
\text { (minimal) }\end{array}$ & No \\
\hline 5 & 77 & 50 & 1 & No & No & 36 & 72 & Alpha & $\begin{array}{l}\text { Theta Beta } \\
\text { Delta }\end{array}$ & No \\
\hline 6 & 80 & 54 & 1 & No & No & 39 & 72 & $\begin{array}{l}\text { Alpha/ } \\
\text { Theta }\end{array}$ & Nil & No \\
\hline 7 & 65 & 21 & 3 & No & No & 15 & 71 & Delta & Theta Alpha & Yes \\
\hline 8 & 92 & 36 & 2 & Yes, visual & No & 4 & 11 & Alpha & Theta Delta & No \\
\hline 9 & 76 & 63 & 2 & No & No & 30 & 48 & Theta & Delta Alpha & No \\
\hline 10 & 54 & 128 & 1 & No & No & 29 & 23 & Alpha & Theta Delta & No \\
\hline 11 & 67 & 57 & 2 & No & No & 33 & 58 & Delta & Theta Beta & No \\
\hline \multicolumn{11}{|l|}{ DLB Patients: } \\
\hline 12 & 85 & 107 & 2 & No & No & 17 & 16 & Alpha & Theta Delta & No \\
\hline 13 & 82 & 32 & 2 & Visual & Yes & 20 & 63 & Alpha & Beta & Yes L \\
\hline 14 Record 1 & 84 & 31 & 2 & Visual & Yes & 24 & 77 & Theta & Delta Beta & No \\
\hline Record 2 & & & & & & & & Theta & Delta & No \\
\hline $15^{2}$ & 84 & 6 & 1 & No & Yes & 5 & 83 & polyrhythmic & $\begin{array}{l}\text { Alpha Theta } \\
\text { Delta }\end{array}$ & Yes L \\
\hline 16 & 72 & 15 & 0.5 & No & No & 4 & 27 & Theta & Beta & No \\
\hline 17 Record 1 & 64 & 41 & 1 & Visual & Yes & 24 & 59 & Alpha & $\begin{array}{l}\text { Delta Theta } \\
\text { beta }\end{array}$ & Yes L \\
\hline Record 2 & & & & & & & & Alpha & Beta Theta & Yes $\mathrm{L} / \mathrm{R}^{\star}$ \\
\hline Record 3 & & & & & & & & Polyrhythmic & Delta Theta & No \\
\hline $18^{3}$ & 84 & 2 & 2 & $\begin{array}{l}\text { Visual and } \\
\text { Auditory }\end{array}$ & No & 1 & 50 & Delta & Theta & No \\
\hline 19 & 68 & 20 & 2 & $\begin{array}{l}\text { Visual and } \\
\text { Auditory }\end{array}$ & No & 11 & 55 & Alpha & Theta Delta & Yes L/R \\
\hline $20^{4}$ & 89 & 22 & 1 & Visual & No & 16 & 73 & Theta & Delta & No \\
\hline 21 & 79 & 27 & 0.5 & No & Yes & 11 & 41 & Theta & Nil & Yes L/R \\
\hline 22 Record 1 & 71 & 32 & 1 & Visual & Yes & 20 & 63 & Delta & Theta & Yes $L / R$ \\
\hline Record $2^{5}$ & & & & & & & & Delta & Theta & Yes L \\
\hline $23^{6}$ & 77 & 24 & 2 & $\begin{array}{l}\text { Visual/olfactory/ } \\
\text { gustatory }\end{array}$ & Yes & 23 & 96 & Delta & Theta & No \\
\hline $\begin{array}{l}24 \text { Record } 1 \\
\text { Record } 2\end{array}$ & 79 & 70 & 2 & No & No & 69 & 99 & $\begin{array}{l}\text { Alpha } \\
\text { Theta }\end{array}$ & $\begin{array}{l}\text { Theta Delta } \\
\text { Alpha }\end{array}$ & $\begin{array}{l}\text { No } \\
\text { Yes L }\end{array}$ \\
\hline 25 & 76 & 120 & 0.5 & No & No & 36 & 30 & $\begin{array}{l}\text { Alpha } \\
\text { Theta }\end{array}$ & Delta & No \\
\hline
\end{tabular}

TLSWT $=$ Temporal lobe slow wave transients

*Increased in number from record 1.

Sharp waves and other EEG features:

${ }^{1}$ Sharp waves on left + right.

${ }^{2}$ Left posterior sharp wave.

${ }^{3}$ Slow waves anteriorly.

${ }^{4}$ Delta dominant anteriorly.

${ }^{5}$ Suggestion of sharp + slow wave complex.

${ }^{6}$ Sharp wave on left side. 
bers in the table. The eleven cases of Alzheimer's disease had a single EEG recorded for each patient. A total of 19 records from 14 patients in the DLB group were examined, because three patients had two records each and one patient had three records. All but patients 2 and 4 (both SDAT) were clearly abnormal with alpha activity decreased outside the normal frequency. Preservation of alpha activity was more common in SDAT $(55 \%)$ than in DLB $(36 \%)(p=0.45)$. One $(9 \%)$ patient with SDAT and seven $(50 \%)$ patients with DLB had no remaining alpha activity. Six (55\%) patients with SDAT and $11(79 \%)$ with DLB had delta components. Overall, this suggests that patients with DLB show a greater tendency towards slowing of both dominant and non-dominant rhythms.

TEMPORAL LOBE SLOW WAVE TRANSIENTS

Temporal lobe slow wave transients were defined as episodes of delta or theta often associated with sharply contoured components but not strictly fulfilling the criteria for spikes (monophasic waves of duration $<80 \mathrm{~ms}$ ) or sharp waves (duration 80-200 ms). They had a duration $<1$ second and occurred in the temporal lobe areas only.

Temporal lobe transients were seen much more often in patients with DLB (seven out of $14(50 \%)$ ) whereas only two $(18 \%)$ of the patients with SDAT showed this abnormality $(p=0.11)$. Nine of the 19 DLB records showed this abnormality.

There was no significant correlation between temporal slow wave transients and either symmetry $(\mathrm{p}=0.57)$ or alpha dominance $(\mathrm{p}=0.19)$.

CORRELATION BETWEEN CLINICAL FEATURES AND TEMPORAL LOBE SLOW WAVE TRANSIENTS

Temporal lobe slow wave transients were highly correlated with reported episodes of loss of consciousness, both in the total group $(p=0.01)$ and within the DLB group $(p=0.05)$ whereas hallucinations $(p=0.5)$, duration of illness $(p=0.59)$, and global severity as measured by CDR $(p=0.51)$ were not.

\section{Discussion}

Electroencephalographic findings in DLB have previously been described only for a few cases. A comprehensive review of the literature found only 13 descriptions of EEGs in DLB confirmed by postmortem..$^{6-9} 1114$

In this study 19 records from 14 patients with DLB confirmed by postmortem were examined. Seventeen of these records were abnormal. The key findings were a loss of alpha activity as the dominant rhythm in 13 of the records, presence of temporal lobe slow wave transients in $50 \%$ of cases, and a strong correlation between the presence of these temporal lobe slow wave transients and a clinical history of loss of consciousness.

Previous reports have commented on this slowing of dominant rhythm ${ }^{511}$ and one author has described a case in which triphasic waves were present. ${ }^{9}$ Periodic synchronous discharges have been described ${ }^{8}$ as have the presence of sharp waves. ${ }^{67}$

No evidence of triphasic waves was found in the records examined, suggesting that this is not a frequent finding in DLB. Only two of the cases described here (5 and 19) had frontal slowing. No cases showed periodic synchronous discharges. Two patients with DLB in this study did had definite sharp waves, in addition to which patient 18 had a single sharp wave, which was not included in the analysis as it was unlikely to have been regarded as relevant in clinical practice.

Episodic loss of consciousness in now considered a supportive feature of DLB in the consensus criteria. The nature of these episodes of loss of consciousness is not clear. Proposed mechanisms ${ }^{14}$ include gait and balance disorder, autonomic instability including postural hypotension, or an epileptic phenomenon. The finding in this paper of a relation between temporal lobe slow wave activity and a clinical history of loss of consciousness is indicative of a primary cerebral dysfunction.

This study is largely a descriptive account of the major EEG findings in DLB. The next step in this work should involve prospective serial EEG examinations from clinically diagnosed patients with DLB followed up to postmortem, with a larger group of patients with SDAT for comparison. An alternative and complimentary approach would be to investigate the role of quantitative EEG analysis in DLB.

We thank Yvonne Wilkin for her help in obtaining EEG records and Maureen Middlemist for typing the manuscript.

1 Perry RH, Irving D, Blessed G, et al. Clinically and pathologically distinct form of dementia in the elderly. Lancet 1989;166.

2 Lennox G, Lowe J, Landon M, et al. Diffuse Lewy body disease: correlative neuropathology using anti-ubiquitin immunocytochemistry. $\mathcal{F}$ Neurol Neurosurg Psychiatry 1989; 52:1236-47.

3 McKeith IG, Fairbairn AF, Perry RH, et al. The clinical diagnosis and misdiagnosis of senile dementia of Lewy
body type (SDLT) - do the diagnostic systems for dementia need to be revised? Br F Psychol 1994;305:324-32.

4 McKeith IG, Galasko D, Kosaka K, et al. Consensus guidelines for the clinical and pathological diagnosis of dementia with Lewy bodies (DLB). Neurology 1996;47:1113-24.

5 Soininen H, Reikkinen PJ. EEG in diagnostics and follow-up of Alzheimer's disease. Acta Neurol Scand

6 Crystal HA, Dickson DW, Lizardi JE, et al. Antemortem diagnosis of diffuse Lewy body disease. Neurology 1990;40: diagnosis 8 .

7 Gibb WR, Luthert PJ, Janota I, et al. Cortical Lewy body dementia: clinical features and classification. $\mathcal{F}$ Neurol Neurosurg Psychiatry 1989;52:185-92.

8 Yamamoto T, Imai T. A case of diffuse Lewy body and Alzheimer's diseases with periodic synchronous discharges. f Neuropathol Exp Neurology 1988;47:536-48.

9 Byrne EJ, Lennox G, Lowe J, et al. Diffuse Lewy body disease: clinical features in 15 cases. $\mathcal{F}$ Neurol Neurosurg Psychiatry 1989;52:709-17.

10 Byrne EJ, Lowe J, Godwin-Austin RB, et al. Dementia and Parkinson's disease associated with diffuse cortical Lewy bodies. Lancet 1987;i:501.

11 Hely MA, Reid WGJ, Halliday GM, et al. Diffuse Lewy body disease: clinical features in nine cases without coexistent AD. fisease: clinical features in nine cases without

12 Perry RH, Irving D, Blessed G, et al. Senile dementia of Lewy body type: a clinically and neuropathologically Lewy body type: a clinically and neuropathologically distinct form of Lewy bo
rol Sci 1990;95:119-39.

13 Hughes PH, Berg L, Danziger WL, et al. A new clinical scale for the staging of dementia. Br F Psychol 1982;140:566-72. 14 McKeith IG, Perry RH, Fairbairn AF, et al. Operational criteria for senile dementia of Lewy body type (DLB). Psychol Med 1992;22:911-22. 